\title{
Pengolahan Tanah Menggunakan Bajak Singkal Lebih Sedikit Memerlukan Air Irigasi daripada Bajak Rotary
}

\section{The Preparation of Land Using Chisel Plow Requires Less Water Requirement than Rotary Plow}

\author{
Gusti Bagus Alit Budi Artawan, I Wayan Tika, Nyoman Sucipta \\ Program Studi Teknik Pertanian, Fakultas Teknologi Pertanian, Universitas Udayana \\ Email: alitbudi@gmail.com
}

\begin{abstract}
Abstrak
Penelitian ini dilakukan untuk mengetahui perbedaan kebutuhan air irigasi pada pengolahan tanah menggunakan bajak singkal dan bajak rotary. Variabel yang diamati dalam penelitian ini meliputi: volume solum, porositas tanah, kadar air awal tanah, kebutuhan air untuk penggenangan, volume genangan, dan lama waktu pengolahan tanah. Lokasi yang digunakan sebagai sampel lahan sawah sebanyak 15 titik sampel untuk masing-masing bajak yang di kelompokan menjadi tiga lokasi yaitu pada hulu, tengah, dan hilir. Pada setiap lokasi diambil lima sampel sawah untuk setiap perlakuan bajak. Volume solum pada sawah yang diolah menggunakan bajak singkal sebesar $2.122,00 \mathrm{~m}^{3} /$ ha sedangkan volume solum menggunakan bajak rotary sebesar $2096,33 \mathrm{~m}^{3} / \mathrm{ha}$. Kadar air awal tanah pada lahan sawah yang digunakan sebagai sampel untuk bajak singkal sebesar 52,98 \% sedangkan pada bajak rotary sebesar 45,63 $\%$. Kebutuhan air untuk penjenuhan lahan sawah yang diolah dengan bajak rotary lebih besar dari bajak singkal yaitu 505,97 $\mathrm{m}^{3} / \mathrm{ha}$, sedangkan pada bajak singkal sebesar $377,11 \mathrm{~m}^{3} / \mathrm{ha}$. Volume genangan pada bajak rotary lebih besar dari bajak singkal yaitu bajak rotary sebesar $401,33 \mathrm{~m}^{3} / \mathrm{ha}$ dan bajak singkal sebesar $141,00 \mathrm{~m}^{3} / \mathrm{ha}$. Untuk lama waktu yang diperlukan untuk mengolah tanah, bajak singkal memerlukan waktu lebih lama yaitu 29,69 jam/ha, sedangkan bajak rotary memerlukan waktu 14,35 jam/ha. Hasil dari penelitian ini menunjukkan pengolahan tanah menggunakan bajak singkal lebih sedikit memerlukan air dibandingkan dengan bajak rotary. Pada pengolahan tanah menggunakan bajak singkal air yang diperlukan yaitu 5,07 1/dt, sedangkan untuk bajak rotary memerlukan air sebanyak 17,69 1/dt.
\end{abstract}

Kata kunci: kebutuhan air irigasi, pengolahan tanah, bajak singkal, bajak rotary.

\begin{abstract}
This research was conducted to know the difference of irrigation water requirement in the preparation of land using chisel plow and rotary plow. The variables observed in this study include: solum volume, soil porosity, initial moisture content of the soil, water requirements for inundation, puddle volume, and duration of soil tillage. Location used as sample of paddy field as much as 15 point sample for each plow which is grouped into three locations that is at upstream, middle, and downstream. At each location five rice samples were taken for each plow treatment. The volume of solum on the treated rice field using the chisel plow of $2122.00 \mathrm{~m} 3$ / ha while the volume of solum using rotary plow of $2.096,33 \mathrm{~m} 3 /$ ha. The initial soil moisture content in paddy field used as sample for chisel plow is $52,98 \%$ while rotary plow is $45,63 \%$. The water requirement for the saturation of paddy field that is processed by rotary plow is bigger than the chisel plow is $505.97 \mathrm{~m} 3$ / ha, whereas in the chisel plow is $377,11 \mathrm{~m} 3 /$ ha. The volume of inundation in the rotary plow is greater than the chisel plow rotary plow of $401.33 \mathrm{~m} 3 /$ ha and chisel plow of $141.00 \mathrm{~m} 3 / \mathrm{ha}$. For the length of time required to cultivate the soil, the chisel plow takes longer time of 29.69 hours / ha, while the rotary plow takes 14.35 hours / ha. The results of this study indicate that the processing of soil using plows of chisel requires less water than the rotary plow. In the processing of the soil using the plot of water chisel required is $5.07 \mathrm{l} / \mathrm{dt}$, while for the rotary plow requires water as much as $17.691 / \mathrm{dt}$.
\end{abstract}

Keywords: irrigation water requirement, soil tillage, chisel plow, rotary plow 


\section{PENDAHULUAN}

Pertanian merupakan salah satu bagian penting dalam kehidupan manusia untuk memenuhi kebutuhan sehari-hari. Kegiatan pertanian tersebut terkait dengan proses persiapan lahan, penanaman, perawatan, pemanenan, dan sampai pada pengolahan hasil panen. Kegiatan pertama yang dilakukan oleh petani dalam bercocok tanam adalah persiapan lahan. Proses persiapan lahan ini berupa kegiatan mengolah tanah agar siap untuk ditanami. Menurut Rizaldi (2006), pengolahan tanah dilakukan pada lahan pertanian bertujuan untuk menciptakan kondisi fisik, dan biologis tanah yang lebih baik dengan suatu kedalaman tertentu agar sesuai bagi pertumbuhan tanaman. Pengolahan tanah (soil tillage) adalah sebuah kegiatan olah tanah yang dilakukan dengan cara tradisional dan modern. Pengolahan tanah secara tradisional masih dilakukan dengan menggunakan hewan ternak untuk membantu menarik bajak, sedangkan secara modern sudah menggunakan traktor sebagai tenaga penariknya. Adapun fungsi dari pengolahan tanah ini yaitu untuk menggemburkan tanah, menghilangkan gulma pada tanah. Untuk mempermudah pengolahan tanah, petani sudah dibantu dengan traktor untuk menarik bajak.

Pekerjaan petani yang berat saat mengolah tanah dapat dipermudah dengan traktor yang dapat dikombinasikan dengan berbagai alat pengolah tanah. Alat-alat yang digunakan petani untuk memotong, mencacah dan membalikkan tanah pada awal pengolahan tanah disebut dengan alat pengolah tanah primer, yang mencangkup bajak singkal, bajak piring, bajak pisau berputar (rotary), dan bajak chisel (Daywin, et al., 2008). Namun bajak yang sering digunakan oleh petani untuk mengolah tanah sawah yaitu bajak singkal dan bajak rotary. Bajak singkal memiliki cara kerja melempar dan membalikkan tanah. Cara tersebut berfungsi untuk menggemburkan tanah yang diolah. Pengolahan tanah dengan bajak singkal menghasilkan bongkahan tanah yang berukuran cukup besar dan berbentuk gumpalan. Untuk mendapatkan hasil tanah yang lebih halus maka diperlukan proses pengolahan lainnya. Sedangkan bajak rotary adalah jenis bajak yang memiliki banyak mata pisau. Mata pisau tersebut berfungsi untuk mencacah tanah serta cukup baik untuk mencacah gulma pada lahan. Untuk memepermudah proses pengolahan tanah pada lahan sawah maka perlu dilakukan pemberian air pada saat akan mengolah tanah. Proses pengolahan tanah pada sawah tidak dapat dipisahkan dari pemberian air. Pemberian air pada saat pengolahan tanah berfungsi untuk menjenuhkan tanah atau memenuhi pori-pori tanah dengan air. Pori-pori tanah yang sudah penuh terisi air akan menyebabkan ikatan antara partikel tanah menjadi melemah, sehingga tanah akan mudah diolah baik menggunakan bajak singkal maupun rotary.

Proses pemberian air pada lahan pertanian dikenal dengan irigasi. Irigasi adalah menyalurkan air yang diperlu untuk pertumbuhan tanaman ke tanah yang diolah dan mendistribusinya secara sistematis (Sosrodarsono dan Takeda, 2003). Pendistribusian tersebut berkaitan dengan pembuatan sarana dan prasarana dalam membagikan air ke sawah-sawah secara teratur. Selain itu juga untuk membuang kelebihan air yang tidak digunakan lagi untuk memenuhi kebutuhan air untuk pertanian lainnya. Kebutuhan air irigasi adalah jumlah volume air yang diperlukan untuk memenuhi kebutuhan evaporasi, kehilangan air, kebutuhan air untuk tanaman dan pengolahan tanah dengan memperhatikan jumlah air yang diberikan oleh alam melalui hujan dan kontribusi air tanah (Anonim, 1996 dalam Manik, 2016).

\section{METODE}

\section{Tempat dan Waktu Penelitian}

Lahan sawah yang digunakan sebagai sampel diambil dari beberapa subak yang dipilih secara acak. Adapun penelitian ini dilaksanakan di Subak Suala di Desa Pitra dan Subak Tegal Linggah di Desa Tegal Linggah sebagai hulu, Subak Gaing di Desa Gulingan sebagai daerah tengah, dan Subak Gubug II di Desa Sudimara sebagai bagian hilir dari pengambilan sampel data. Untuk pengukuran porositas tanah dilakukan di Lab. Pengelolaan Sumberdaya Alam, Fakultas Teknologi Pertanian, Universitas Udayana. Waktu pelaksanaan penelitian dilakukan pada Bulan Juli 2017 sampai September 2017.

\section{Alat dan Objek Penelitian}

Peralatan yang digunakan dalam penelitian ini adalah : traktor bajak singkal, bajak rotary, ring sampel tanah, papan triplek, karet gelang, kain kasa, kantong plastik, pisau, oven, timbangan, cawan air, tongkat kayu, penggaris, dan kamera. Adapun spesifikasi dari traktor yang digunakan untuk menarik bajak yaitu mesin yang digunakan adalah mesin disel berbahan bakar solar dan menghasilkan tenaga sebesar 10 PK. Dan objek yang diamati adalah air irigasi dan sampel tanah yang diambil pada setiap petak sawah.

\section{Variabel Penelitian}


Variabel tersebut dibedakan menjadi dua yaitu variabel bebas dan variabel tergantung. Variabel bebas dalam penelitian ini yaitu kebutuhan air irigasi untuk pengolahan tanah. Sedangkan yang menjadi variabel tergantung yaitu volume solum, kadar air awal tanah, kebutuhan air untuk penjenuhan, volume genangan, dan lama waktu pengolahan tanah.

\section{Prosedur Penelitian}

Penelitian ini mengamati proses pengolahan tanah dengan menggunakan dua jenis bajak yang berbeda yaitu bajak singkal dan bajak rotary. Pengambilan data dilakukan di beberapa lokasi yang sudah ditentukan. Pengukuran kedalaman solum dilakukan mengunakan tongkat kayu dan penggaris. Tongkat kayu ditancapkan kedalam tanah kemudian tongkat kayu yang sudah ditancapkan diukur kembali menggunakan penggaris untuk mengetahui berapa kedalaman solum dari sampel lahan. Untuk pengukuran tinggi genangan juga diukur menggunakan tongkat kayu dan penggaris. Tinggi genangan yang diukur yaitu tinggi air dari permukaan tanah. Pengukuran dilakukan dengan cara menancapkan tongkat kayu pada lapisan air sampai menyentuh permukaan tanah kemudian tongkat kayu yang telah ditancapkan diukur kembali dengan penggaris. Pengukuran porositas tanah dilakukan dengan cara mengambil sampel tanah dari lahan sawah menggunakan ring sampel tanah. Setelah mengambil sampel tanah kemudian dilakukan pengukuran porositas tanah di laboratorium. Jika semua pengukuran selesai dilakukan kemudian dilakukan tabulasi data, dimana semua data yang dibutuhkan untuk analisis ditempatkan dalam bentuk tabel.

\section{Analisis Data}

Penelitian ini melalui dua tahapan analisis. Tahapan pertama yang dilakukan pada analisis data adalah mengkompilasi data pengukuran kedalaman solum, porositas tanah dan tinggi genangan yang sudah diukur pada beberapa lokasi yang berbeda. Dari data hasil pengukuran tersebut selanjutnya dilakukan perhitungan volume solum, kadar air awal tanah, kebutuhan air untuk penjenuhan, volume genangan, lama waktu pengolahan tanah, dan kebutuhan air irigasi pada saat pengolahan tanah. Setelah mendapatkan hasil perhitungan kebutuhan air irigasi, tahapan selanjutnya yang dilakukan adalah melakukan analisis data dengan menggunakan Uji-t. Uji ini dilakukan untuk mengetahui apakah ada perbedaan kebutuhan air irigasi antara pengolahan menggunakan bajak singkal dan bajak rotary.

\section{HASIL DAN PEMBAHASAN}

\section{Kebutuhan Air Irigasi Saat Pengolahan Tanah}

Kebutuhan air irigasi adalah jumlah volume air yang diperlukan untuk memenuhi kebutuhan evaporasi, kehilangan air, kebutuhan air untuk tanaman dengan memperhatikan jumlah air yang diberikan oleh alam melalui hujan dan kontribusi air tanah (Susrodarsono dan Takeda, 2003). Secara langsung di lapangan pengukuran kebutuhan air irigasi saat pengolahan tanah dapat dilakukan dengan menjumlahkan nilai kebutuhan air untuk penjenuhan, volume genangan, perkolasi, evaporasi dan kemudian dibagi dengan lama waktu pengolahan tanah. Semua nilai tersebut didapatkan dengan cara mengukur kedalaman solum, tinggi genangan, dan porositas tanah yang diukur dari sampel tanah.

\section{Volume Solum}

Volume solum tanah didapatkan dengan cara mengukur kedalaman dari lahan sawah yang digunakan sebagai sampel. Pengukuran dilakukan pada lima titik untuk setiap petak sawah dan ditentukan secara diagonal. Setelah mendapatkan nilai kedalaman solum maka, dapat dihitung nilai volume solum perhektarnya. Data hasil perhitungan volume solum dapat dilihat pada Tabel 1. Adapun persamaan yang digunakan untuk menghitung volume solum yaitu seperti rumus nomer (1).

\section{$\mathrm{V}_{\text {solum }}=$ kedalaman solum $\mathrm{x}$ luas, lahan}

Dimana: $\mathrm{V}_{\text {solum }}=$ volume solum $\left(\mathrm{m}^{3} / \mathrm{ha}\right)$; kedalaman solum (m); luas lahan $\left(\mathrm{m}^{2}\right)$.

Tabel 1. Nilai volume solum sampel lahan sawah.

\begin{tabular}{|c|c|c|c|}
\hline \multirow{2}{*}{ No. } & \multirow{2}{*}{ Lokasi } & \multicolumn{2}{|c|}{ Volume Solum $\left(\mathrm{m}^{3 / \mathrm{ha}}\right)$} \\
\cline { 3 - 4 } & & Baiak Singkal & Bajak Rotary \\
\hline 1 & Hulu & 1875.00 & 1935.00 \\
\hline 2 & Hulu & 2040.00 & 1885.00 \\
\hline 3 & Hulu & 2065.00 & 1840.00 \\
\hline 4 & Hulu & 2385.00 & 1930.00 \\
\hline 5 & Hulu & 2310.00 & 1910.00 \\
\hline 6 & Tengah & 2330.00 & 2295.00 \\
\hline 7 & Tengah & 2270.00 & 2080.00 \\
\hline 8 & Tengah & 2325.00 & 2215.00 \\
\hline 9 & Tengah & 2210.00 & 2590.00 \\
\hline 10 & Tengah & 2820.00 & 1995.00 \\
\hline 11 & Hilii & 2295.00 & 1980.00 \\
\hline 12 & Hilir & 2080.00 & 2360.00 \\
\hline 13 & Hilii & 1785.00 & 2135.00 \\
\hline 14 & Hilir & 1490.00 & 2105.00 \\
\hline 15 & Hilir & 1550.00 & 2190.00 \\
\hline & Rata-rata & 2122.00 & 2096.33 \\
\hline
\end{tabular}

Data dari hasil perhitungan volume solum disajikan pada Tabel 1. Dari Tabel 1 dapat dilihat nilai rata-rata volume solum pada lahan yang diolah dengan bajak singkal lebih besar dari bajak rotary. Nilai rata-rata volume solum pada sawah yang diolah menggunakan 
bajak singkal sebesar $2122,00 \mathrm{~m}^{3} /$ ha sedangkan volume solum menggunakan bajak rotary sebesar $2096,33 \mathrm{~m}^{3} / \mathrm{ha}$. Pada setiap lokasi sampel lahan sawah terlihat memiliki nilai volume solum yang sedikit berbeda pada masing-masing bajak. Yang menyebabkan volume solum antar bajak singkal dan bajak rotary memiliki sedikit perbedaan yaitu karena pengamatan penelitian ini hanya dilakukan pada satu periode tanan. Selain itu pada periode tanam sebelumnya tidak diketahui bajak apa yang digunakan untuk mengolah tanah. Untuk mengetahui perbedaan volume solum yang jelas antara kedua bajak tersebut harus dilakukan pengamatan dalam jangka waktu yang lebih lama atau dalam beberapa periode tanam.

\section{Kadar Air Awal Tanah}

Kadar air awal tanah dihitung untuk mengetahui jumlah air yang tersedia pada tanah saat sebelum digenangi air pada saat akan diolah. Pengukuran kadar air awal tanah dilakukan dengan mengurangi berat awal sampel tanah yang sudah diambil dengan berat kering sampel tanah yang sudah dioven. Data hasil perhitungan solum dapat dilihat pada Tabel 2 . Adapun persamaan yang digunakan untuk menghitung kadar air awal tanah yaitu seperti rumus nomer (3).

Kadar air awal tanah $=\frac{B A-B K}{V_{\tan a h}} \times 100 \% .$. atau,

$$
\frac{V_{\text {air }}}{V_{\text {tan } a h}} x 100 \%
$$

Dimana: Kadar air awal tanah (\%); BA = berat awal sampel tanah (gr); BK = berat kering sampel tanah (gr); $\mathrm{V}_{\text {air }}=$ volume air sampel tanah $\left(\mathrm{cm}^{3}\right)$ didapat dari berat air dikali dengan berat jenis air $\left(1 \mathrm{gr} / \mathrm{cm}^{3}\right) ; \mathrm{Vtanah}=$ volume sampel tanah $\left(\mathrm{cm}^{3}\right)$.

Tabel 2

Nilai kadar air awal tanah sampel lahan sawah.

\begin{tabular}{|c|c|c|c|}
\hline \multirow{2}{*}{ No. } & \multirow{2}{*}{ Lokasi } & \multicolumn{2}{|c|}{ Kadar air awal tanah (\%) } \\
\hline & & Bajak Singkal & Bajak Rotary \\
\hline 1 & Hulu & 56.36 & 45.27 \\
\hline 2 & Hulu & 48.66 & 42.91 \\
\hline 3 & Hulu & 50.82 & 47.18 \\
\hline 4 & Hulu & 54.13 & 43.71 \\
\hline 5 & Hulu & 49.12 & 41.63 \\
\hline 6 & Tengah & 54.78 & 45.83 \\
\hline 7 & Tengah & 46.50 & 54.38 \\
\hline 8 & Tengah & 57.07 & 46.14 \\
\hline 9 & Tengah & 49.18 & 45.53 \\
\hline 10 & Tengah & 52.79 & 48.63 \\
\hline 11 & Hilir & 55.64 & 47.29 \\
\hline 12 & Hilir & 54.83 & 46.09 \\
\hline 13 & Hilir & 55.34 & 44.18 \\
\hline 14 & Hilir & 52.90 & 47.97 \\
\hline 15 & Hilir & 56.56 & 37.64 \\
\hline & a-rata & 52.98 & 45.63 \\
\hline
\end{tabular}

Hasil pengukuran kadar air awal tanah disajikan pada Tabel 2. Dilihat dari Tabel 2 nilai rata-rata kadar air awal tanah pada bajak singkal lebih besar dibandingkan dengan bajak rotary. Perbedaan nilai rata-rata kadar air tanah pada masing-masing bajak terlihat sangat besar. Pada bajak singkal kadar air awal tanah sebesar 52,98 \% sedangkan pada bajak rotary sebesar $45,63 \%$.

\section{Kebutuhan Air Untuk Penjenuhan}

Kebutuhan air untuk penjenuhan tanah didapatkan dari selisih antara porositas tanah setelah pengolahan tanah dengan kadar air awal tanah. Setelah mendapatkan nilai selisih tersebut selanjutnya dikalikan dengan volume solum dari sampel lahan sawah. Hasil perhitungan dari kebutuhan air untuk penjenuhan dapat dilihat pada Tabel 3. Persamaan yang digunakan untuk menghitung kebutuhan air untuk penjenuhan dapat dilihat pada persamaan nomer (4).

\section{Penjenuhan $=($ porositas - kadar air awal tanah $) \times$ Voolum}

Dimana: penjenuhan $\left(\mathrm{m}^{3} / \mathrm{ha}\right)$; porositas $(\%)$; kadar air awal tanah $(\%) ; \mathrm{V}_{\text {solum }}=$ volume solum $\left(\mathrm{m}^{3} / \mathrm{ha}\right)$.

Tabel 3

Nilai kebutuhan air untuk penjenuhan lahan. 


\begin{tabular}{|c|c|c|c|}
\hline \multirow{2}{*}{ No. } & \multirow{2}{*}{ Lokasi } & \multicolumn{2}{|c|}{ Kebutuhan air untuk penjenuhan $\left(\mathrm{m}^{3} / \mathrm{ha}\right)$} \\
\cline { 3 - 4 } & & Bajak Singkal & Bajak Rotary \\
\hline 1 & Hulu & 360.94 & 616.49 \\
\hline 2 & Hulu & 475.93 & 559.28 \\
\hline 3 & Hulu & 402.06 & 537.65 \\
\hline 4 & Hulu & 413.80 & 595.79 \\
\hline 5 & Hulu & 409.33 & 576.25 \\
\hline 6 & Tengah & 465.07 & 566.87 \\
\hline 7 & Tengah & 529.36 & 347.98 \\
\hline 8 & Tengah & 361.07 & 513.88 \\
\hline 9 & Tengah & 400.23 & 773.12 \\
\hline 10 & Tengah & 674.83 & 382.84 \\
\hline 11 & Hilir & 300.65 & 371.05 \\
\hline 12 & Hilir & 342.16 & 367.69 \\
\hline 13 & Hilir & 146.01 & 445.15 \\
\hline 14 & Hilir & 189.98 & 374.27 \\
\hline 15 & Hilir & 185.29 & 561.30 \\
\hline \multicolumn{2}{|r|}{ Rata-rata } & 377.11 & 505.97 \\
\hline
\end{tabular}

Data hasil perhitungan kebutuhan air untuk penjenuhan didapatkan seperti pada Tabel 3. Dapat dilihat pada Tabel 3 nilai rata-rata kebutuhan air untuk penjenuhan pada lahan sawah untuk setiap bajak sangat berbeda. Nilai rata-rata kebutuhan air untuk penjenuhan pada bajak rotary lebih besar dari pada bajak singkal. Pada bajak rotary rata-rata kebutuhan air untuk penjenuhan sebesar 505,97 $\mathrm{m}^{3} /$ ha, sedangkan pada bajak singkal sebesar 377,11 $\mathrm{m}^{3} / \mathrm{ha}$.

\section{Volume Genangan}

Volume genangan didapatkan dengan cara mengukur tinggi genangan air yang diberikan oleh petani ke lahan sawah. Pengukuran ketinggian genangan dilakukan secara diagonal dengan mengambil lima titik ukur untuk setiap sampel lahan sawah. Setelah mendapatkan tinggi genangan maka, dapat dihitung nilai volume genangan perhektarnya. Data hasil perhitungan volume genengan dapat dilihat pada Tabel 4. Persamaan yang digunakan untuk menghitung volume genangan yaitu seperti rumus nomer (5).

\section{$\mathrm{V}_{\text {genangan }}=$ tinggi genangan $\mathrm{x}$ luas lahan}

Dimana: $\mathrm{V}_{\text {genangan }}=$ volume genangan $\left(\mathrm{m}^{3} / \mathrm{ha}\right)$; tinggi genangan $(\mathrm{m})$; luas lahan $\left(\mathrm{m}^{2}\right)$.

\section{Tabel 4}

Nilai volume genangan pada sampel lahan sawah.

\begin{tabular}{|c|c|c|c|}
\hline \multirow{2}{*}{ No. } & \multirow{2}{*}{ Lokasi } & \multicolumn{2}{|c|}{ Volume genangan $\left(\mathrm{m}^{3} / \mathrm{ha}\right)$} \\
\hline & & Bajak Singkal & Bajak Rotary \\
\hline 1 & Hulu & 195.00 & 495.00 \\
\hline 2 & Hulu & 260.00 & 400.00 \\
\hline 3 & Hulu & 235.00 & 380.00 \\
\hline 4 & Hulu & 150.00 & 510.00 \\
\hline 5 & Hulu & 30.00 & 545.00 \\
\hline 6 & Tengah & 25.00 & 550.00 \\
\hline 7 & Tengah & 270.00 & 480.00 \\
\hline 8 & Tengah & 100.00 & 365.00 \\
\hline 9 & Tengah & 180.00 & 365.00 \\
\hline 10 & Tengah & 125.00 & 460.00 \\
\hline 11 & Hilit & 5.00 & 315.00 \\
\hline 12 & Hilir & 90.00 & 245.00 \\
\hline 13 & Hilit & 135.00 & 365.00 \\
\hline 14 & Hilir & 145.00 & 300.00 \\
\hline 15 & Hilit & 170.00 & 245.00 \\
\hline & a-rata & 141.00 & 401.33 \\
\hline
\end{tabular}

Data hasil perhitungan volume solum disajikan pada Tabel 4. Dari Tabel 4 dapat dilihat nilai rata-rata volume genangan pada lahan sawah yang diolah dengan bajak singkal dan bajak rotary sangat berbeda. Volume genangan pada bajak rotary lebih besar dari bajak singkal yaitu bajak rotary sebesar $401,33 \mathrm{~m}^{3} /$ ha dan bajak singkal sebesar 141,00 $\mathrm{m}^{3} / \mathrm{ha}$. Perbedaan volume genangan antar lahan sawah yang diolah dengan bajak singkal dan bajak rotary dikarenakan kekuatan dari kedua bajak tersebut berbeda. Perbedaan kekuatan bajak tersebut dikarenakan sistem keja bajak yang berbeda. Bajak singkal memiliki sistem kerja memotong dan membalikkan tanah sedangkan bakak rotary memiliki sistem kerja berputar untuk mencacah tanah oleh karena itu bajak singkal lebih kuat mengolah tanah dengan genangan air yang sedikit.

\section{Lama Waktu Pengolahan Tanah}

Waktu yang dibutuhkan untuk mengolah tanah berbeda-beda untuk setiap bajak. Lama waktu pengolahan tanah yang dimaksud yaitu berapa lama waktu yang diperlukan untuk mengolah tanah seluas satu hektar. Data hasil perhitungan lama waktu pengolahan tanah disajikan pada Tabel 5. Adapun persamaan untuk menghitung lama waktu pengolahan tanah yaitu dapat dilihat pada rumus nomer (6).

\section{Lama waktu pengolahan tanah $=\quad$ total jam keria total lahan yang diolah}

Dimana: Lama waktu pengolahan tanah (jam/ha); total jam kerja (jam); total lahan yang diolah (ha). 
Tabel 5

Lama waktu pengolahan tanah.

\begin{tabular}{|c|c|c|c|}
\hline \multirow{2}{*}{ No. } & \multirow{2}{*}{ Lokasi } & \multicolumn{2}{|c|}{ Lama waktu pengolahan tanah (jam/ha) } \\
\cline { 3 - 4 } & & Bajak Singkal & Bajak Rotary \\
\hline 1 & Hulu & 32.00 & 15.24 \\
\hline 2 & Hulu & 35.56 & 16.84 \\
\hline 3 & Hulu & 26.67 & 14.55 \\
\hline 4 & Hulu & 32.00 & 18.82 \\
\hline 5 & Hulu & 45.71 & 16.00 \\
\hline 6 & Tengah & 24.62 & 12.80 \\
\hline 7 & Tengah & 32.00 & 13.91 \\
\hline 8 & Tengah & 26.67 & 12.31 \\
\hline 9 & Tengah & 21.33 & 13.33 \\
\hline 10 & Tengah & 24.62 & 14.55 \\
\hline 11 & Hilir & 29.09 & 13.33 \\
\hline 12 & Hilir & 35.56 & 12.80 \\
\hline 13 & Hilir & 32.00 & 15.24 \\
\hline 14 & Hilir & 24.62 & 12.80 \\
\hline 15 & Hilir & 22.86 & 12.80 \\
\hline \multicolumn{2}{|c|}{ Rata-rata } & 29.69 & 14.35 \\
\hline
\end{tabular}

Data hasil perhitungan lama waktu pengolahan tanah dapat dilihat pada Tabel 5. Dari Tabel 5 dapat dilihat nilai rata-rata waktu pengolahan tanah dengan bajak singkal dan bajak rotary memiliki perbedaan yang jelas. Bajak singkal memerlukan waktu yang lebih lama untuk mengolah tanah dibandingkan dengan bajak rotary. Nilai rata-rata waktu yang diperlukan untuk mengolah tanah pada bajak singkal yaitu 29,69 jam/ha, sedangkan bajak rotary memerlukan waktu 14,35 jam/ha. Lama waktu pengolahan tanah pada kedua bajak tersebut disebabkan karena lebar kerja dari masing-masing bajak berbeda. Lebar kerja menggunakan bajak singal lebih kecil dibandingan dengan bajak rotary. Sehingga pada luas lahan yang sama bajak singkal memerlukan waktu yang lebih lama untuk mengolah tanah dari bajak rotary.

\section{Perkolasi dan Evaporasi}

Perkolasi merupakan peroses kelanjutan aliran air dari proses infiltrasi ke lapisan tanah yang lebih dalam (Asdak, 2007). Besar perkolasi pada bulan dilaksanakan penelitian sebesar $4 \mathrm{~mm} / \mathrm{hari} \mathrm{di}$ Kabupaten Tabanan. Nilai perkolasi tersebut diasumsikan sama dengan nilai perkolasi di Kabupaten Badung karena penelitian ini dilaksanakan pada lokasi yang berbeda.

Evaporasi merupakan proses penguapan air yang berasal dari permukaan bentangan air atau dari bahan padat yang mengandung air (Lakitan, 1994). Besar evaporasi di Kabupaten Tabanan pada bulan dilaksanakan penelitian sebesar $5 \mathrm{~mm} /$ hari. Dan untuk di Kabupaten Badung diasumsikan besar nilai evaporasinya sama.

\section{Kebutuhan Air Irigasi}

Setelah mengetahui semua nilai dari variabel yang diperlukan maka, perhitung kebutuhan air irigasi pada saat pengolahan tanah baru bisa dilakukan. Hasil dari perhitungan kebutuhan air irigasi dapat dilihat seperti pada Tabel 6. Persamaan yang digunakan untuk menghitung kebutuhan air irigasi untuk pengolahan tanah yaitu seperti pada rumus (7).

$$
K A I=\frac{\text { Penjenuhan }+V_{\text {gtnergen }}+\text { Perkolas } i+\text { Evaporas } i}{T_{\text {alek }}}
$$

Dimana: $\mathrm{KAI}=$ kebutuhan air irigasi $(1 / \mathrm{dt} / \mathrm{ha})$; $\mathrm{V}_{\text {genangan }}=$ volume genangan $\left(\mathrm{m}^{3} / \mathrm{ha}\right)$; perkolasi ( $\left.\mathrm{m}^{3} / \mathrm{jam}\right)$; evaporasi $\left(\mathrm{m}^{3} / \mathrm{jam}\right)$; $\mathrm{T}_{\text {olah }}=$ lama waktu pengolahan tanah (jam/ha).

Data hasil penelitian mengenai kebutuhan air irigasi pada saat pengolahan tanah yaitu disajikan pada Tabel 2. Dilihat dari Tabel 2 nilai rata-rata kebutuhan air pada saat pengolahan tanah menggunakan bajak singkal lebih kecil dari bajak rotary. Perbedaan kebutuhan air irigasi dari kedua bajak tersebut cukup besar. Kebutuhan air irigasi menggunakan bajak singkal sebesar 5,07 1/dt, sedangkan kebutuhan air irigasi dengan menggukan bajak rotary lebih besar yaitu 17,69 1/dt. Dari hasil uji statistik t-Test yang dilakukan menyatakan terdapat perbedaan dari pengolahan tanah menggunakan bajak singkal atau bajak rotary pada kebutuhan air irigasi pada saat pengolahan tanah. Perbedaan kebutuhan air irigasi untuk pengolahan tanah tersebut dikarenakan bajak rotary memerlukan kondisi tanah yang lebih lunak agar lebih mudah untuk diolah.

Tabel 6. Kebutuhan air irigasi untuk mengolah tanah.

\begin{tabular}{|c|c|c|c|}
\hline \multirow{2}{*}{ No. } & \multirow{2}{*}{ Lokasi } & \multicolumn{2}{|c|}{ Kebutuhan air irigasi (1/dt) } \\
\cline { 3 - 4 } & & Bajak Singkal & Bajak Rotary \\
\hline 1 & Hulu & 4.86 & 20.33 \\
\hline 2 & Hulu & 5.78 & 15.88 \\
\hline 3 & Hulu & 6.67 & 17.60 \\
\hline 4 & Hulu & 4.93 & 16.37 \\
\hline 5 & Hulu & 2.69 & 19.53 \\
\hline 6 & Tengah & 5.57 & 24.32 \\
\hline 7 & Tengah & 6.97 & 16.61 \\
\hline 8 & Tengah & 4.84 & 19.92 \\
\hline 9 & Tengah & 7.60 & 23.79 \\
\hline 10 & Tengah & 9.07 & 16.17 \\
\hline 11 & Hilir & 2.95 & 14.37 \\
\hline 12 & Hilir & 3.41 & 13.38 \\
\hline 13 & Hilir & 2.47 & 14.84 \\
\hline 14 & Hilir & 3.82 & 14.71 \\
\hline 15 & Hilir & 4.36 & 17.58 \\
\hline \multicolumn{2}{|r|}{ Rata-rata } & 5.07 & 17.69 \\
\hline
\end{tabular}

Bajak rotary memerlukan kondisi tanah yang lunak agar pisau bajak dapat berputar dengan baik. Untuk membuat tanah mudah untuk diolah diperlukan 
jumlah air yang lebih banyak untuk memenuhi ruang pori tanah sehingga ikatan antar pori tanah menjadi lemah karena terisi penuh oleh air. Sedangkan pengolahan tanah dengan menggunakan bajak singkal dapat dilakukan dengan mudah dalam kondisi sedikit air atau macak-macak.

\section{KESIMPULAN DAN SARAN}

\section{Kesimpulan}

Dari hasil penelitian yang dilakukan terhadap beberapa variabel pengamatan dapat disimpulkan sebagai berikut:

1. Kebutuhan air irigasi pada saat pengolahan tanah menggunakan bajak singkal sebesar 5,07 1/dt, sedangkan dengan menggunakan bajak rotary sebesar 17,69 1/dt.

2. Dari hasil penelitian yang telah dilaksanakan didapatkan bahwa kebutuhan air irigasi pada saat pengolahan tanah menggunakan bajak singkal dan rotary berbeda.

\section{Saran}

Berdasarkan dari penelitian ini disarankan yaitu:

1. Perlu dikaji lebih lanjut kebutuhan air irigasi pada saat pengolahan tanah dengan mengkombinasikan penggunaan bajak.

2. Perlu dikaji kembali jenis tanah apakah berpengaruh pada kebutuhan air irigasi pada saat pengolahan tanah selain dari penggunaan bajak.

\section{DAFTAR PUSTAKA}

Anonim. 1996, Diktat Kuliah Irigasi dan Bangunan Air, Cisarua.

Asdak, C. 2007. Hidrologi dan Pengelolaan Daerah Aliran Sungai. Gadjah Mada University Press. Yogyakarta.

Daywin,FJ, RG. Sitompul, Imam Hidayat. 2008. MesinMesin Budidaya Pertanian di Lahan Kering. Graha Ilmu. Yogyakarta.

Lakitan, B., 1994. Dasar-dasar Klimatologi. Raja Grafindo Persada, Jakarta.

Rizaldi, T. 2006. Mesin Peralatan. Departemen Teknologi Pertanian FP-USU. Medan.

Sosrodarsono, Suyono dan Takeda, Kensaku. 2003. Hidrologi untuk Pengairan. Pradna Paramita, Jakarta. 